Edited by:

Kathleen S. Rockland, Massachusetts

Institute of Technology, USA

Reviewed by:

Kathleen S. Rockland, Massachusetts

Institute of Technology, USA

Barbara Clancy, University of Central

Arkansas, USA

*Correspondence:

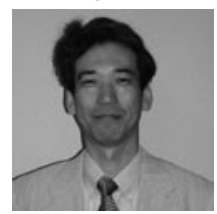

Nobuaki Tamamaki is the Chair of the Department of Morphological Neural Science, in Graduate School of Medical Sciences at the Kumamoto University. His research focuses on Analysis of hippocampal circuit by intracellular single cell labeling, developmental neurobiology, neurogenesis, and cell migration. He obtained his $P h D$ at the Graduate School of Science at Osaka

University.

tamamaki@kumamoto-u.ac.jp

\title{
Long-range GABAergic connections distributed throughout the neocortex and their possible function
}

\author{
Nobuaki Tamamaki ${ }^{1 *}$ and Ryohei Tomioka ${ }^{2}$ \\ 1 Department of Morphological Neural Science, Graduate School of Medical Sciences, Kumamoto University, Kumamoto, \\ Japan \\ 2 Center for Brain Research, Medical University of Vienna, Vienna, Austria
}

Features and functions of long-range GABAergic projection neurons in the developing cerebral cortex have been reported previously, although until now their significance in the adult cerebral cortex has remained uncertain. The septo-hippocampal circuit is one exception - in this system, long-range mature GABAergic projection neurons have been well analyzed and their contribution to the generation of theta-oscillatory behavior in the hippocampus has been documented. To have a clue to the function of the GABAergic projection neurons in the neocortex, we view how the long-range GABAergic projections are integrated in the cortico-cortical, cortico-fugal, and afferent projections in the cerebral cortex. Then, we consider the possibility that the GABAergic projection neurons are involved in the generation, modification, and/or synchronization of oscillations in mature neocortical neuron activity. When markers that identify the GABAergic projection neurons are examined in anatomical and developmental studies, it is clear that neuronal NO synthetase (nNOS)-immunoreactivity can readily identify GABAergic projection neurons. GABAergic projection neurons account for $0.5 \%$ of the neocortical GABAergic neurons. To elucidate the role of the GABAergic projection neurons in the neocortex, it will be necessary to clarify the network constructed by nNOS-positive GABAergic projection neurons and their postsynaptic targets. Thus, our long-range goals will be to label and manipulate (including deleting) the GABAergic projection neurons using genetic tools driven by a nNOS promoter. We recognize that this may be a complex endeavor, as most excitatory neurons in the murine neocortex express nNOS transiently. Nevertheless, additional studies characterizing long-range GABAergic projection neurons will have great value to the overall understanding of mature cortical function.

Keywords: GABA, GABAergic projection neuron, gamma-oscillations, neocortex, nNOS

Neuroanatomical studies in a wide variety of mammals identify two types of cortical neurons, the excitatory glutamatergic neurons, and the inhibitory GABAergic neurons. By convention the glutamatergic neurons are considered the sole originators of long-range cortico-fugal and cortico-cortical projections. GABAergic neurons, which account for $15-25 \%$ of cortical neurons (Jones, 1993) are termed "interneurons," typically are described as projecting a highly ramified axon locally. However, it would be more accurate to call the subset of locally projecting inhibitory neurons "GABAergic interneurons" to distinguish them from locally projecting glutamatergic 
GABAergic projection neuron Neurons which release GABA as an inhibitory transmitter. Usually, GABAergic neurons possess locally ramified axon. However, a GABAergic projection neuron has an axon projecting long distance. There are many GABAergic neurons with long projection axon in the brain stem and some in the neocortex.

Gamma-oscillation

Gamma-oscillations are patterns of brain waves with a frequency between 30 and $100 \mathrm{~Hz}$, though $40 \mathrm{~Hz}$ are prototypical. According to a popular theory, gamma waves may be implicated in creating the unity of conscious perception (the binding problem). However, there is no agreement on the theory. neurons, as well as from the less well studied subset of GABAergic neurons that extend longrange projections. The role of the long-range GABAergic projection neurons in the neocortex is not clear.

There has been increasing interest in the roles of GABAergic interneurons in the neocortex, including in their role in oscillatory behavior. Neuronal oscillations may be a fundamental mechanism for establishing memory, perception, and consciousness. In the case of recognizing an event or an object based on perception via multimodal cortical areas, oscillations in multiple cortical areas may need to be synchronized via long-range neuronal connections. These may originate in excitatory neurons, or inhibitory neurons, or both. Excitatory neurons excite parvalbumin (PV)-positive GABAergic interneurons (Kawaguchi et al., 1987). These PV neurons synapse onto the perisomatic surface and proximal axon segments of a cluster of excitatory neurons and inhibit spiking behavior. As the results of interconnected local circuits, probability of spike discharges in an excitatory neuron changes from time to time and shows high-frequency oscillation (gamma-oscillation) (Whittington et al., 1995; Mann and Mody, 2010). Singer and his colleagues hypothesized that the gamma-oscillations are indispensable to enhance information processing in the cerebral cortex (König et al., 1996; Womelsdorf et al., 2007). A cluster of excitatory neurons also have the potential to activate one another reciprocally via ultra-fast current flow through gap junctions located around the proximal axon segment, which is also believed to enhance the gamma-oscillation in the hippocampus (Traub and Bibbig, 2000). Recently, however, opto-genetic experiments have attributed the major role in creating the gamma-oscillation to the PV neurons (Cardin et al., 2009; Sohal et al., 2009). Synchronization of gamma-oscillation in two separated cortical areas may be achieved by excitatory fibers terminating on PV neurons in the other area (Traub et al., 1996; Whittington et al., 1997). At the same time, neurons in the two cortical areas may need to be connected reciprocally and symmetrically so as to enable cortical resonance. The resonance may enhance the number of spikes arriving at a peak of gammaoscillation and attenuate the number of off-peak spikes (Uhlhaas and Singer, 2010). As the result, gamma-oscillations in multiple cortical areas may be synchronized. In this focused review, we would like to explore the possibility that not only GABAergic interneurons but also GABAergic projection neurons are involved in such important brain functions.

\section{GABAergic LONG NETWORKS INVOLVING NEOCORTEX}

Based on the accumulated information by many neuroanatomists, here we will take the opportunity to focus on the wiring by GABAergic longrange neuronal connections in the brain. We first examine the literature related to GABAergic neurons with cortico-fugal, and subcortical afferent axons (Figure 1).

GABAergic interneurons are categorized into several subtypes based on characteristic expression profiles of peptides and proteins (Kubota et al., 1994; Gonchar and Burkhalter, 1997) or physiological properties (Miles et al., 1996; Markram et al., 2004; Puig et al., 2008). These characteristics are also applicable to the GABAergic projection neurons (Figure 1). For example, medial septal GABAergic neurons are positive for PV and terminate preferentially on hippocampal GABAergic neurons (Freund and Antal, 1988).

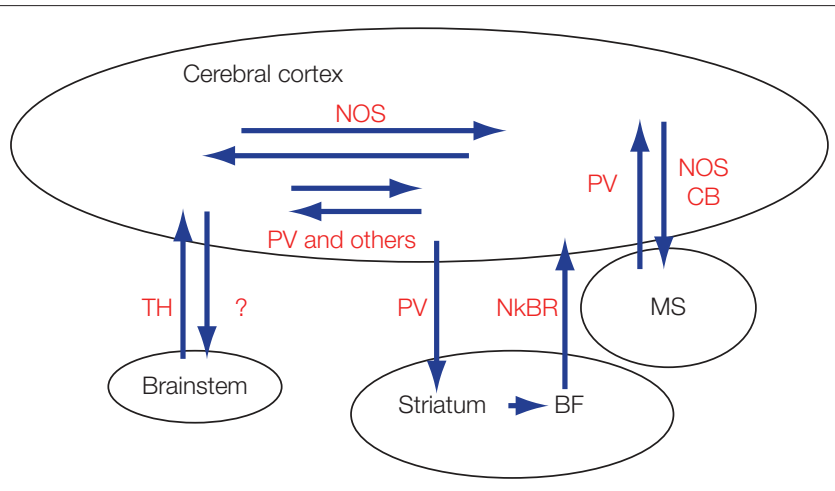

FIGURE 1 | Currently reported cortico-cortical, cortico-fugal, and afferent GABAergic projections. Most of these GABAergic projection neurons express characteristic protein or peptides. $B F$, basal forebrain; $C B$, calbindin; $M S$, medial septum; NkBR, neurokinin-B receptor; nNOS, neuronal NO synthetase; PV, parvalbumin; SS, somatostatin; TH, tyrosine hydroxylase. 
Disinhibition

GABA neurons inhibit other neurons by releasing GABA. When another GABA neurons inhibit the previous GABA neurons, inhibition to the other neurons is cancelled. Another GABA neurons disinhibited other neurons.

Theta-oscillation

In rodents, theta rhythmicity is easily observed in the hippocampus, but can also be detected in numerous other cortical and subcortical brain structures. Hippocampal theta, with a frequency range of $6-10 \mathrm{~Hz}$, appears when a rat is engaged in active motor behavior such as walking or exploratory sniffing, and also during REM sleep.
A subset of the hippocampal GABAergic neurons, which often contain calbindin (CB), somatostatin (SS), or neuronal NO synthetase (nNOS), project axons to the medial septum and innervate the PV-positive GABAergic neurons (Tóth and Freund, 1992; Tóth et al., 1993; Jinno, 2009).

When medial septal GABAergic neurons inhibit GABAergic neurons in the hippocampus, so as to cancel inhibition to pyramidal neurons, the pyramidal neurons are allowed to fire (Tóth et al., 1997). The cancellation of inhibition (disinhibition) in the hippocampus is terminated by the inhibitory input to the PV neurons in the medial septum. This disinhibiting septo-hippocampal circuit (and its negative feedback loop) was found by recording large field potentials in the hippocampus following stimulation of the fimbria (Bilkey and Goddard, 1987). The circuit for "disinhibition" was analyzed anatomically, and in agreement with the in vivo electrophysiology results, reciprocal projections between GABAergic neurons were found (Freund and Antal, 1988). Subsequent electrophysiological studies in vitro revealed that the septo-hippocampal circuit generates theta-oscillation in the hippocampus (Heynen and Bilkey, 1991; Tóth et al., 1997).

Non-pyramidal neurons in the cat hippocampal formation project to the mammillary body (Ino et al., 1988). Tyrosine hydroxylase (TH)positive GABAergic neurons in the A13 subdivision of the zona incerta project to the neocortex (Lin et al., 1990). The neocortex, striatum, and basal forebrain are connected by different subtypes of GABAergic projections. A small number of PV-positive GABAergic neurons in the somatosensory area project axons to the striatum (Jinno and Kosaka, 2004). Neurokinin-B positive GABAergic neurons in the striatum project to neurokinin-B receptor-positive GABAergic neurons in the basal forebrain which project axons to the cerebral cortex (Furuta et al., 2004). However, functions of these projections remain to be elucidated.

\section{SOME GABAergic NEURONS HAVE LONG- RANGE PROJECTION AXONS IN THE NEOCORTEX}

In retrograde labeling studies of excitatory neurons, tracers, such as WGA-HRP, fast blue (FB), and fluorogold, were injected into axon terminal areas and detected in the neuronal somata, after retrograde axonal transport. Retrograde labeling combined with immunohistochemistry of GAD or GABA, or other modified nNOS labeling methods correlated with morphology of retrogradely labeled neurons revealed that GABAergic neurons project axons to remote neocortical regions in the ipsilateral hemisphere (McDonald and Burkhalter, 1993; Albus and Wahle, 1994; Aroniadou-Anderjaska and Keller, 1996; Fabri and Manzoni, 1996) and in the contralateral hemisphere (Peters et al., 1990; Gonchar et al., 1995; Fabri and Manzoni, 2004; Tomioka et al., 2005; Higo et al., 2009). These cortico-cortical GABAergic projections are also found in the connections between cortical areas (Tomioka and Rockland, 2007) and between allocortices (Ino et al., 1990; van Haeften et al., 1997; Jinno, 2009). Indeed, microstimulation of the neocortex elicits monosynaptic inhibitory postsynaptic potentials (IPSPs) that are not preceded by excitation in a small number of neurons in the remote ipsilateral cortex (Ghosh and Porter, 1988; Salin and Prince, 1996).

To simplify the procedures and to increase the sensitivity of detecting GABAergic projection neurons in the neocortex, we produced a glutamic acid decarboxylase 67 (GAD67) -green fluorescent protein (GFP) knock-in mouse (Tamamaki et al., 2003), and performed FB retrograde labeling experiments in the mouse (Tomioka et al., 2005). We plotted GFP- and FB-double-labeled cells in the entire neocortical area and characterized the GABAergic projection neurons by immunohistochemistry (Figure 2). In the study we found FB-singlelabeled cells (excitatory projection neurons) are accompanied by a small number of GFP- and FB-double-labeled cells (GABAergic projection neurons) in most cases of the retrograde labeling (Figure 2D). We also found several cortical regions that contained FB- and GFPdouble-labeled cells, but few FB-single-labeled cells. This mismatch between the distribution of FB-single-labeled cells and that of FB- and GFPdouble-labeled cells implies that GABAergic projections may be distributed more widely over ipsilateral neocortical areas than excitatory projections in the mouse.

\section{CORTICO-CORTICAL GABAergic PROJECTION NEURONS ARE POSITIVE FOR nNOS}

Depending on the projection distance, the retrogradely labeled subtypes of GABAergic neurons vary greatly (Tomioka et al., 2005; Tomioka and Rockland, 2007). Within $1.5 \mathrm{~mm}$ of the tracerinjection site, many retrogradely labeled GABAergic neurons exhibit immunoreactivity for PV, SS, or calretinin (CR) in all the neocortical layers in mice. At increasing distances, the retrogradely labeled GABAergic neurons predominantly express SS-IR. Finally, in cortical regions more than $1.5 \mathrm{~mm}$ from the injection site, almost all of the retrogradely labeled GABAergic neurons express SS-IR in the 


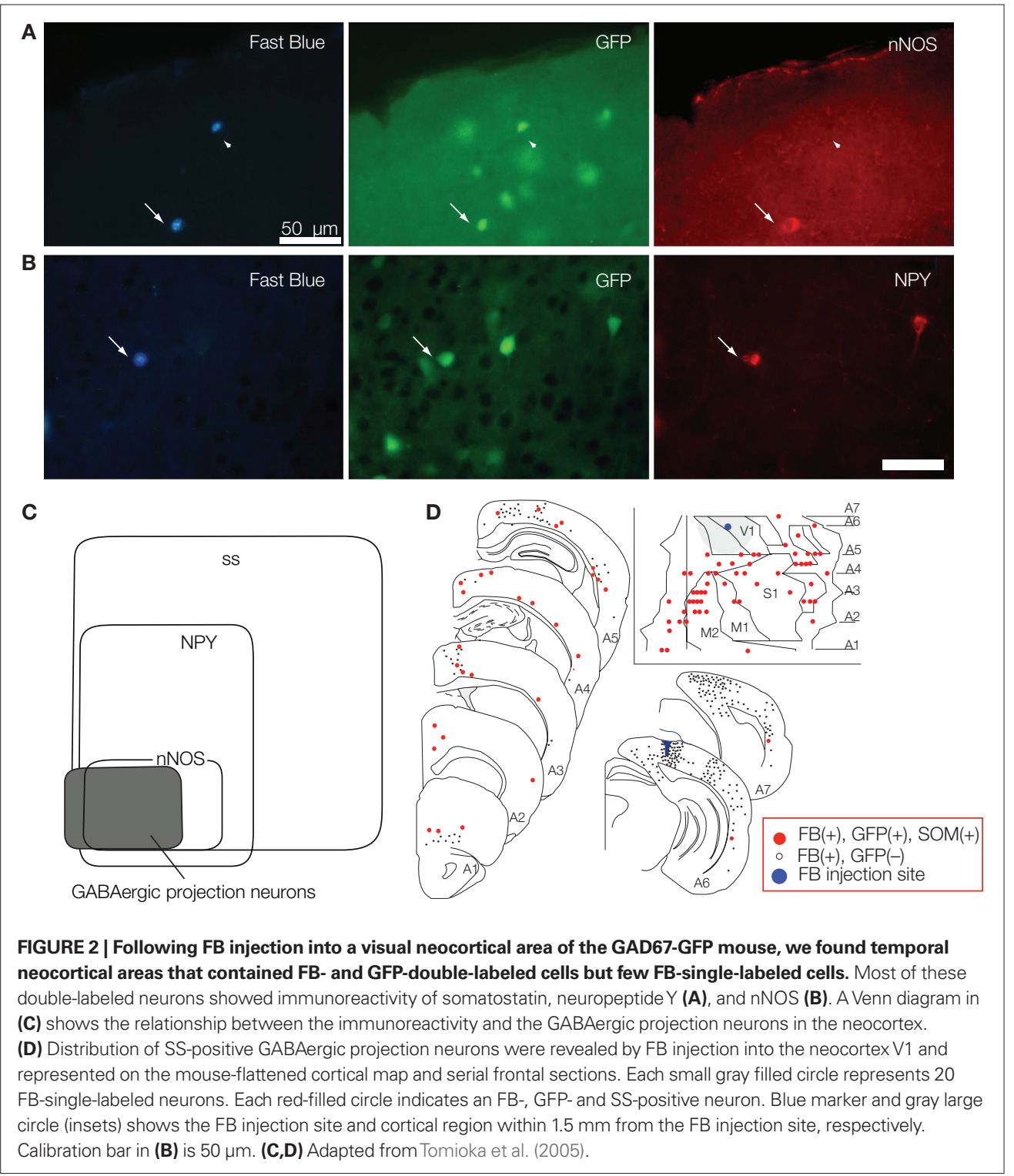

deepest layer of the neocortex, or in the white matter and layer I. Although GABAergic projections in the archicortex and paleocortex originate in the gray matter and layers II-V, respectively (van Haeften et al., 1997; Jinno, 2009), the actual distance of these projections may be less than $1.5 \mathrm{~mm}$ in rodent. The GABAergic commissural projection, which is longer than $1.5 \mathrm{~mm}$, originates in the deepest layer of the neocortex (Gonchar et al., 1995), and the laminar distribution of the GABAergic projection neurons mimics that of nNOS-positive type 1 neurons in rats and monkeys (Yan et al., 1996; Yan and Garey, 1997). Consistent with this observation, GABAergic projection neurons positive for SS, NPY, and nNOS (91, 82, and $71 \%$, respectively) have been identified. The more that is learned about the features of GABAergic projection neurons, the more they appear to be similar to the nNOS-positive type 1 neurons in the neocortex. An intracellular labeling study revealed that the nNOS-positive subplate neurons give rise to projecting axon longer than $1.5 \mathrm{~mm}$ (Clancy et al., 2001).

Notably, the nNOS-positive neurons consist of two different subpopulations in rats and monkeys (Yan and Garey, 1997; Smiley et al., 2000): one is characterized by CB-IR, small somata, and low $\mathrm{NADPH}$-diaphorase activity (type II neurons) and the other by a lack of CB-IR, large somata, and intense NADPH-diaphorase activity (type I neurons) (Kubota et al., 1994; Yan et al., 1996; Gonchar and Burkhalter, 1997; Smiley et al., 2000). Yan and Garey (1997) suggested that the vast majority of the nNOS-positive neurons in the mouse neocortex are the CB-negative type I neurons. Considering these observations, we speculate that the vast majority of cortico-cortical GABAergic projection 
neurons in the mouse express nNOS. nNOSpositive GABAergic neurons account for $1 \%$ in rat (Gonchar and Burkhalter, 1997). Taking all these factors into consideration, we speculate that GABAergic projection neurons account for $0.5 \%$ of the neocortical GABAergic neurons in mouse.

Several possible functions of nNOS in the central nervous system have been suggested, including the regulation of glutamate release (Kano et al., 1998) and of capillary dilatation (Cauli et al., 2004), but we do not yet know how the nNOS, NPY, and SS expressed by GABAergic projection neurons function in the neocortex. It is known that GABAergic projection neurons in the white matter receive neocortical excitatory inputs as a major neuronal input, but these cells do not appear to receive significant thalamic input (Shering and Lowenstein, 1994; Okhotin and Kalinichenko, 2003, Tomioka et al., 2005).

To examine the function of GABAergic projection neurons, the primary approach will be to observe the morphology of projection axons, especially their terminal arborization, and to identify their postsynaptic target cells. It is also important to find roles only GABAergic projection neurons can play in the neocortex. An important clue to the function of GABAergic projection neurons may be inferred from the organization of the corpus callosum. The corpus callosum contains the commissural fibers of excitatory neurons and those of GABAergic neurons (Peters et al., 1990; Gonchar et al., 1995; Fabri and Manzoni, 2004; Tomioka et al., 2005; Higo et al., 2009). The latter may be selected from transient GABAergic commissural fibers (Cobas et al., 1988; Kimura and Baughman, 1997) and are stabilized for interhemispheric communication beyond early developmental stages. In the case of sectioning of the corpus callosum, the gamma-oscillations were de-synchronization between the two hemispheres (Figure 3) (Engel et al., 1991; Uhlhaas and Singer, 2010). Thus, we may be able to test how excitatory fibers and GABAergic fibers in the corpus callosum contribute to synchronize the gamma-oscillation by specific ablation or blocking of either fiber system. Since the mechanism for generating gamma-oscillation is not solely attributable to excitatory neurons,

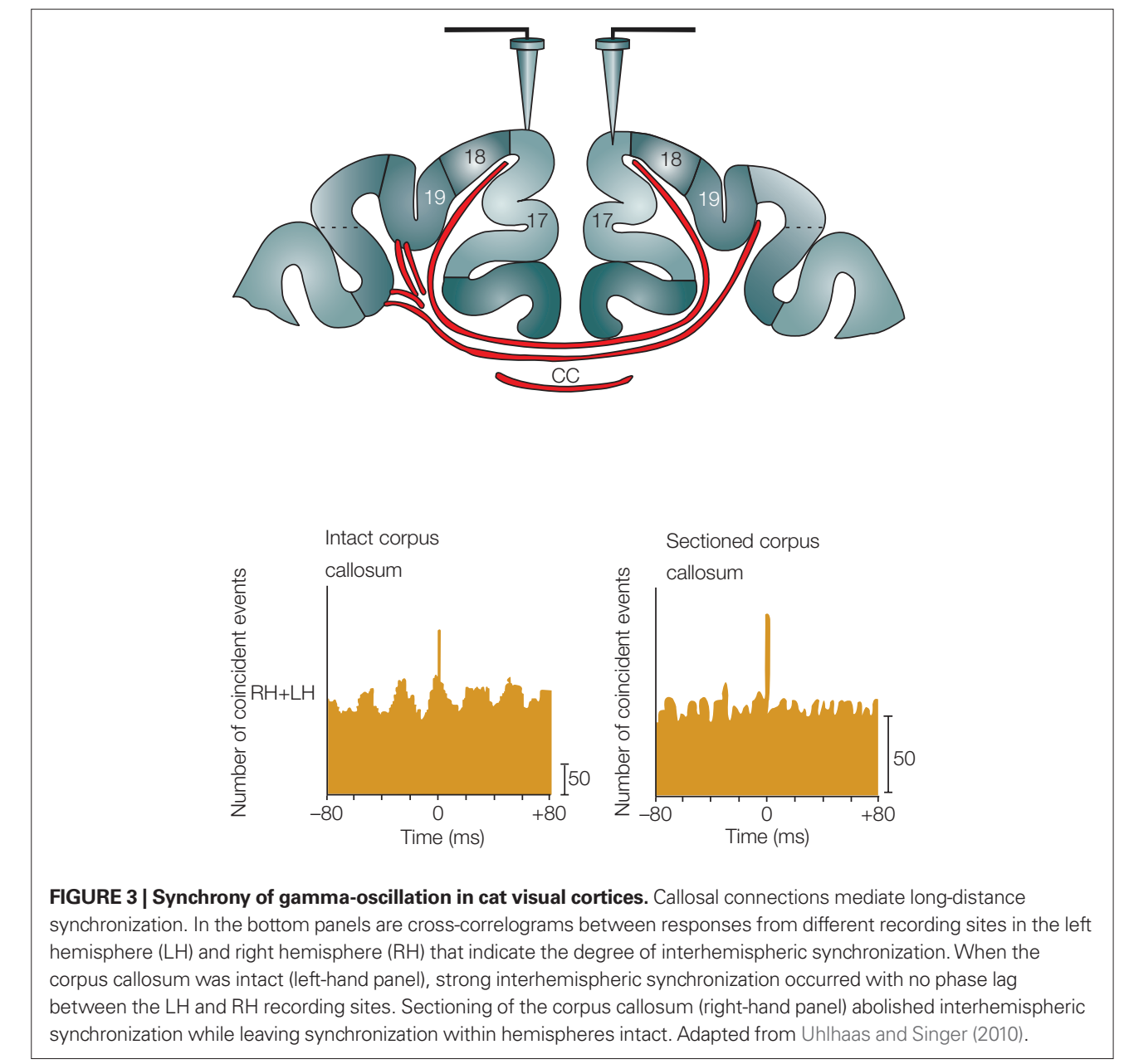


it is possible that the mechanism for synchronizing the gamma-oscillations in multiple cortical areas is also not attributable solely to excitatory neurons. GABAergic projection neurons in the neocortex may make an important contribution to the synchrony of gamma-oscillations. We speculate that GABAergic projection fibers may release GABA and adjust the spike timing of excitatory neurons and PV neurons through GABAa receptor-mediated quick IPSPs.

\section{ORIGIN AND DEVELOPMENT OF nNOS- POSITIVE GABAergic PROJECTION NEURONS}

As discussed above, we speculate that nNOS-positive GABAergic projection neurons are involved in important brain functions. To address the function of nNOS-positive GABAergic projection neurons in vivo, there are several tools that can silence, activate, or delete the neurons in question, such as, channelrhodopsin-2 variant (Lin et al., 2009), light-activated electrogenic $\mathrm{Cl}(-)$ pump (Gradinaru et al., 2008), and diphtheria toxin receptor (Kuyama et al., 2010). In any case, we need information of a marker specific to GABAergic projection neurons. In the following, we discuss why nNOS may be a useful marker for GABAergic projection neurons in the neocortex.

It is widely accepted that during the development of the mammalian neocortex, subplate neurons (Shatz et al., 1988; McConnell et al., 1989; Finney et al., 1998) and marginal zone neurons (Meyer et al., 1998) extend cortico-fugal pioneering axons. It is also accepted that the subplate neurons are transient targets of thalamocortical axons, and although some then undergo apoptosis, some remain in the mature cortex as white-matter neurons (Chun and Shatz, 1989a; Kanold and Luhmann, 2010). There is another term "early generated neurons" for the neurons in the embryonic neocortex. This term seems to include three different cell groups. One of the groups is Cajal-Retzius cells in the marginal zone, which are GABA-negative and originate in the pallial edge (Takiguchi-Hayashi et al., 2004; Bielle et al., 2005). Another group is GABA-negative preplate neurons which originate in the ventricular zone of the neocortex. A recent study clarified that the cortico-fugal pioneer fibers originate from the GABA-negative preplate neurons, which are segregated during development into marginal zone neurons and subplate neurons (Espinosa et al., 2009). A third group is composed of GABAergic neurons originating in the ganglionic eminence migrating tangentially to the neocortex (Anderson et al., 1997; Tamamaki et al., 1997b). Early generated GABAergic neurons are distributed broadly in the marginal zone, subplate, and the intermediate zone (IZ). In cat neocortex, the subplate GABAergic neurons are often positive for somatostatin, neuropeptide $\mathrm{Y}$, and nNOS (Chun et al., 1987; Chun and Shatz, 1989b). Those in the rat subplate are also positive for nNOS (Clancy et al., 2001). Although Bayer and Altman (1991) regard the rat layer VII (VIb) as the subplate and ignore the GABAergic neurons distributed sparsely in the white matter, GABAergic neurons in the rat white matter accumulate in the medial edge of the white matter (around the cingulate bundle) (Figure 4). A number of white-matter neurons in the cingulate have axons projecting to the spinal cord (Figure 4 and Tamamaki et al., 1997a). Since a part of the white-matter neurons are maintained

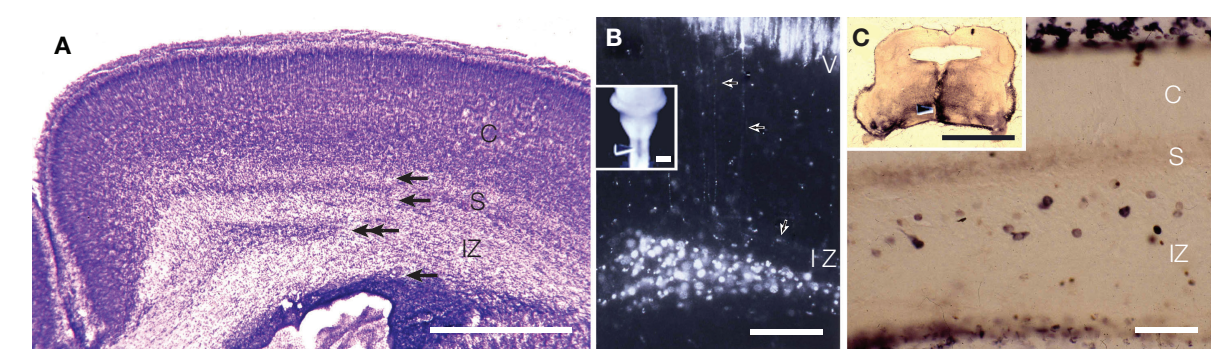

FIGURE 4 | GABAergic subplate neurons in the intermediate zone (IZ) also extend their axon cortico-fugally. (A) Postnatal day 0 rat neocortex. Top and second arrows indicate the width of subplate according to Bayer and Altman (1991). Second and third arrows indicate the width of white matter which contains many GABAergic neurons. Doublearrows indicate the area where we found retrogradely labeled neurons after lipophilic red fluorescent dye, Dil injection into the median plane of the spinal cord. See insets in (B). (B) Dil injection into the spinal cord (C1-C3) at P0 labeled pyramidal neurons in layer $\mathrm{V}$ and subplate neurons in the IZ. Axons of pyramidal neurons followed those of GABAergic subplate neurons rather than those of GABA-negative subplate neurons (layer VII). (C) Biotin-dextan-amine (BDA) injection into the primordium of pons at E18 rat labeled subplate neurons in the IZ at P0. CP, cortical plate; IZ, intermediate zone; S, subplate containing excitatory subplate neurons. Arrow heads in the insets in (B,C) indicate the injection site of Dil and BDA. Calibration bars in (A), and in the insets in $(\mathbf{B}, \mathbf{C})$ are $1 \mathrm{~mm}$. Calibration bar in (B) is $100 \mu \mathrm{m}$, that in $(\mathbf{C})$ is $50 \mu \mathrm{m}$. (B) Adapted from Tamamaki et al. (1997a,b). 
even after birth and may originate axon branches to innervate several neocortical regions, they can be identified as GABAergic projection neurons in the neocortex. In a similar way, the nNOS-positive GABAergic neurons in the marginal zone may be identified as GABAergic projection neurons in layer II.

Based on the information shown above, we hope to label and manipulate (including delete) the GABAergic projection neurons in vivo by an application of genetic tools driven by nNOS promoters. However, since in mice all excitatory neurons in the neocortex also express nNOS transiently by 2 weeks postnatal days, the process of experimentation will be complex.

\section{ACKNOWLEDGMENTS}

The authors acknowledge valuable preview of the manuscript and kind advices by Drs. Roger Traub and Wen-Jie Song.

\section{REFERENCES}

Albus, K., and Wahle, P. (1994). The topography of tangential inhibitory connections in the postnatally developing and mature striate cortex of the cat. Eur. J. Neurosci. 6, 779-792.

Anderson, S.A., Eisenstat,D.D., Shi, L., and Rubenstein, J. L. (1997). Interneuron migration from basal forebrain to neocortex: dependence on Dlx genes. Science 278, 474-476.

Aroniadou-Anderjaska, V., and Keller, A. (1996). Intrinsic inhibitory pathways in mouse barrel cortex. Neuroreport 7, 2363-2368.

Bayer, S. A., and Altman, J. (1991). Neocortical Development. New York: Raven Press.

Bielle, F., Griveau, A., Narboux-Nême, N., Vigneau, S., Sigrist, M., Arber, S., Wassef, M., and Pierani, A. (2005). Multiple origins of Cajal-Retzius cells at the borders of the developing pallium. Nat. Neurosci. 8, 1002-1012.

Bilkey, D. K., and Goddard, G. V. (1987). Septohippocampal and commissural pathways antagonistically control inhibitory interneurons in the dentate gyrus. Brain Res. 405, 320-325.

Cardin, J. A., Carlén, M., Meletis, K., Knoblich, U., Zhang, F., Deisseroth, K., Tsai, L. H., and Moore, C. I. (2009). Driving fast-spiking cells induces gamma rhythm and controls sensory responses. Nature 459, 663-667.

Cauli, B., Tong, X. K., Rancillac, A., Serluca, N., Lambolez, B., Rossier, J., and Hamel, E. (2004). Cortical GABA interneurons in neurovascular coupling: relays for subcortical vasoactive pathways. J. Neurosci. 24, 8940-8949.

Chun, J. J., Nakamura, M. J., and Shatz, C. J. (1987). Transient cells of the developing mammalian telencephalon are peptide-immunoreactive neurons. Nature 325, 617-620.

Chun, J. J., and Shatz, C. J. (1989a). Interstitial cells of the adult neocortical white matter are the remnant of the early generated subplate neuron population. J. Comp. Neurol. 282, 555-569.
Chun, J. J., and Shatz, C. J. (1989b). The earliest-generated neurons of the cat cerebral cortex: characterization by MAP2 and neurotransmitter immunohistochemistry during fetal life. J. Neurosci. 9, 1648-1667.

Clancy, B.,Silva-Filho, M., and Friedlander, M. J. (2001).Structure and projections of white matter neurons in the postnatal rat visual cortex. J. Comp. Neurol. 434, 233-252.

Cobas, A., Alvarez-Bolado, G., and Fairén, A. (1988). Transient GABA-like immunoreactive axons in the corpus callosum of perinatal rats. Neurosci. Lett. 93, 7-12.

Engel, A. K., Kreiter, A. K., König, P., and Singer, W. (1991). Synchronization of oscillatoryneuronal responses between striate and extrastriate visual cortical areas of the cat. Proc. Natl. Acad. Sci. U.S.A. 88, 6048-6052.

Espinosa, A., Gil-Sanz, C., Yanagawa, Y., and Fairén, A. (2009). Two separate subtypes of early non-subplate projection neurons in the developing cerebral cortex of rodents. Front. Neuroanat. 3:27. doi: 10.3389/ neuro.05.027.2009.

Fabri, M., and Manzoni, T. (1996). Glutamate decarboxylase immunoreactivity in corticocortical projecting neurons of rat somatic sensory cortex. Neuroscience 72, 435-448.

Fabri, M., and Manzoni, T. (2004). Glutamic acid decarboxylase immunoreactivity in callosal projecting neurons of cat and rat somatic sensory areas. Neuroscience 123, 557-566.

Finney, E. M., Stone, J. R., and Shatz, C. J. (1998). Major glutamatergic projection from subplate into visual cortex during development. J. Comp. Neurol. 398, 105-118.

Freund, T. F., and Antal, M. (1988). GABA-containing neurons in the septum control inhibitory interneurons in the hippocampus. Nature 336, 170-173.

Furuta, T., Koyano, K., Tomioka, R., Yanagawa, Y., and Kaneko, T. (2004). GABAergic basal forebrain neurons that express receptor for neurokinin $B$ and send axons to the cerebral cortex. J. Comp. Neurol. 473, 43-58.

Ghosh, S., and Porter, R. (1988). Corticocortical synaptic influences on morphologically identified pyramidal neurons in the motor cortex of the monkey. J. Physiol. 400, 617-629.

Gonchar, Y., and Burkhalter, A. (1997) Three distinct families of GABAergic neurons in rat visual cortex. Cereb. Cortex 7, 347-358.

Gonchar, Y. A., Johnson, P. B., and Weinberg, R. J. (1995). GABAimmunopositive neurons in rat neocortex with contralateral projections to S-I. Brain Res. 697, 27-34.

Gradinaru, V., Thompson, K. R., and Deisseroth, K. (2008). eNpHR: a natronomonas halorhodopsin enhanced for optogenetic applications. Brain Cell Biol. 36, 129-139.

Heynen, A. J., and Bilkey, D. K. (1991). Induction of RSA-like oscillations in both the in-vitro and in-vivo hippocampus. Neuroreport 2, 401-404.

Higo, S., Akashi, K., Sakimura, K., and Tamamaki, N. (2009). Subtypes of GABAergic neurons project axons in the neocortex. Front. Neuroanat. 3:25. doi: 10.3389/neuro.05.025.2009.

Ino, T., Itoh, K., Kamiya, H., Shigemoto, R., Akiguchi, I., and Mizuno, N. (1988). Direct projections of non-pyramidal neurons of Ammon's horn to the supramammillary region in the cat. Brain Res. 460, 173-177.

Ino, T., Matsuzaki, S., Shinonaga, Y., Ohishi, H., Ogawa-Meguro, R., and Mizuno, N. (1990). Direct projections of non-pyramidal neurons of Ammon's horn to the amygdala and the entorhinal cortex. Neurosci. Lett. $115,161-166$

Jinno, S. (2009). Structural organization of long-range GABAergic projection system of the hippocampus. Front. Neuroanat. 3:13. doi: 10.3389/ neuro.05.013.2009.

Jinno, S., and Kosaka, T. (2004) Parvalbumin is expressed in glutamatergic and GABAergic corticostriatal pathway in mice. J. Comp. Neurol.477, 188-201.
Jones, E. G. (1993). GABAergic neurons and their role in cortical plasticity in primates. Cereb. Cortex 3, 361-372.

Kano, T., Shimizu-Sasamata, M., Huang, P. L., Moskowitz, M. A., and Lo, E. H. (1998). Effects of nitric oxide synthase gene knockout on neurotransmitter release in vivo. Neuroscience 86 , 695-699.

Kanold, P. O., and Luhmann, H. J. (2010). The subplate and early cortical circuits. Annu. Rev. Neurosci. 33, 23-48.

Kawaguchi, Y., Katsumaru, H., Kosaka, T., Heizmann, C. W., and Hama, K. (1987). Fast spiking cells in rat hippocampus (CA1 region) contain the calcium-binding protein parvalbumin. Brain Res. 16, 369-374.

Kimura, F., and Baughman, R. W. (1997). GABAergic transcallosal neurons in developing rat neocortex. Eur. J. Neurosci. 9, 1137-1143.

König, P., Engel, A. K., and Singer, W. (1996) Integrator or coincidence detector? The role of the cortical neuron revisited. Trends Neurosci. 19 130-137.

Kubota, Y., Hattori, R., and Yui, Y. (1994). Three distinct subpopulations of GABAergic neurons in rat frontal agranular cortex. Brain Res. 649, 159-173.

Kuyama, M., Kayama, H., Atarashi, K., Saiga, H., Kimura, T., Waisman, A., Yamamoto, M., and Takeda, K. (2010). A novel in vivo inducible dendritic cell ablation model in mice. Biochem. Biophys. Res. Commun. 397, 559-563.

Lin, C. S., Nicolelis, M. A., Schneider, J. S., and Chapin, J. K. (1990). A major direct GABAergic pathway from zona incerta to neocortex. Science 248 , 1553-1556.

Lin, J. Y., Lin, M. Z., Steinbach, P., and Tsien, R.Y. (2009). Characterization of engineered channelrhodopsin variants with improved properties and kinetics. Biophys. J. 96, 1803-1814.

Mann, E. O., and Mody, I. (2010). Control of hippocampal gamma oscillation frequency by tonic inhibition and excitation of interneurons. Nat. Neurosci. 13, 205-212. 
Markram, H., Toledo-Rodriguez, M., Wang, Y., Gupta, A., Silberberg, G., and $\mathrm{Wu}, \mathrm{C}$. (2004). Interneurons of the neocortical inhibitory system. Nat. Rev. Neurosci. 5, 793-807.

McConnell, S. K., Ghosh, A., and Shatz, C. J. (1989). Subplate neurons pioneer the first axon pathway from the cerebral cortex. Science 245, 978-982.

McDonald, C. T., and Burkhalter, A. (1993). Organization of long-range inhibitory connections with rat visual cortex. J. Neurosci. 13, 768-781.

Meyer, G., Soria, J. M., Martinez-Galan, J. R., Martin-Clemente, B., and Fairen,A. (1998). Different origins and developmental histories of transient neurons in the marginal zone of the fetal and neonatal rat cortex. J. Comp. Neurol. 397, 493-518.

Miles, R., Tóth, K., Gulyás, A. I., Hájos, N., and Freund, T. F. (1996). Differences between somatic and dendritic inhibition in the hippocampus. Neuron 16, 815-623.

Okhotin, V. E., and Kalinichenko, S. G. (2003). Subcortical white matter interstitial cells: their connections, neurochemical specialization, and role in the histogenesis of the cortex. Neurosci. Behav. Physiol. 33, 177-194.

Peters, A., Payne, B. R., and Josephson, K. (1990). Transcallosal non-pyramidal cell projections from visual cortex in the cat. J. Comp. Neurol. 302, 124-142.

Puig, M.V., Ushimaru, M., and Kawaguchi, Y. (2008). Two distinct activity patterns of fast-spiking interneurons during neocortical UP states. Proc. Natl. Acad. Sci. U.S.A. 105, 8428-8433.

Salin, P. A., and Prince, D. A. (1996). Electrophysiological mapping of GABAA receptor-mediated inhibition in adult rat somatosensory cortex. J. Neurophysiol. 75, 1589-1600.

Shatz, C. J., Chun, J. J. M., and Luskin, M. B. (1988). "The role of the subplate in the development of the mammalian telencephalon," in Cerebral Cortex:
Development and Maturation of Cerebral Cortex, eds A. Peters and E. G. Jones (New York: Plenum Press), 35-58.

Shering, A. F., and Lowenstein, P. R. (1994). Neocortex provides direct synaptic input to interstitial neurons of the intermediate zone of kittens and white matter of cats: a light and electron microscopic study. J. Comp. Neurol. 347, 433-443.

Smiley, J. F., McGinnis, J. P., and Javitt, D. C. (2000). Nitric oxide synthase interneurons in the monkey cerebral cortex are subsets of the somatostatin, neuropeptide $\mathrm{Y}$, and calbindin cells. Brain Res. 863, 205-212.

Sohal, V. S., Zhang, F., Yizhar, O., and Deisseroth, K. (2009). Parvalbumin neurons and gamma rhythms enhance cortical circuit performance. Nature 459, 698-702.

Takiguchi-Hayashi, K., Sekiguchi, M., Ashigaki, S., Takamatsu, M., Hasegawa, H., Suzuki-Migishima, R., Yokoyama, M., Nakanishi, S., and Tanabe, Y. (2004). Generation of reelin-positive marginal zone cells from the caudomedial wall of telencephalic vesicles. J. Neurosci. 24, 2286-2295.

Tamamaki, N., Fujimori, K. E., and Takauji, R. (1997a). Intermediate zone and intermediate zone neurons. Do IZ neurons acts as pioneers for layer $\mathrm{V}$ neurons in rats? Dev. Neurosci. 19, 112-126.

Tamamaki, N., Fujimori, K. E., and Takauji, R. (1997b). Origin and route of tangentially migrating neurons in the developing neocortical intermediate zone. J. Neurosci. 17, 8313-8323.

Tamamaki, N., Yanagawa, Y., Tomioka, R., Miyazaki, J., Obata, K., and Kaneko, T. (2003). Green fluorescent protein expression and colocalization with calretinin, parvalbumin, and somatostatin in the GAD67-GFP knock-in mouse. J. Comp. Neurol. 467, 60-79.

Tomioka, R., Okamoto, K., Furuta, T., Fujiyama, F., Iwasato, T., Yanagawa, Y.,
Obata, K., Kaneko, T., and Tamamaki, N. (2005). Demonstration of longrange GABAergic connections distributed throughout the mouse neocortex. Eur. J. Neurosci. 21, 1587-1600.

Tomioka, R., and Rockland, K. S. (2007). Long-distance corticocortical GABAergic neurons in the adult monkey white and gray matter. J. Comp. Neurol. 505, 526-538.

Tóth, K., Borhegyi, Z., and Freund, T. F. (1993). Postsynaptic targets of GABAergic hippocampal neurons in the medial septum-diagonal band of broca complex. J. Neurosci. 13, 3712-3724.

Tóth, K., and Freund, T. F. (1992) Calbindin D28k-containing nonpyramidal cells in the rat hippocampus: their immunoreactivity for GABA and projection to the medial septum. Neuroscience 49, 793-805.

Tóth, K., Freund, T. F., and Miles, R. (1997). Disinhibition of rat hippocampal pyramidal cells by GABAergic afferents from the septum. J. Physiol. 500, 463-474.

Traub, R. D., and Bibbig, A. (2000). A model of high-frequency ripples in the hippocampus based on synaptic coupling plus axon-axon gap junctions between pyramidal neurons. $J$. Neurosci. 20, 2086-2093.

Traub, R. D., Whittington, M.A., Stanford, I. M., and Jefferys, J. G. (1996). A mechanism for generation of longrange synchronous fast oscillations in the cortex. Nature 383, 621-624.

Uhlhaas, P. J., and Singer, W. (2010). Abnormal neural oscillations and synchrony in schizophrenia. Nat. Rev. Neurosci. 11, 100-113.

van Haeften, T., Wouterlood, F. G., Jorritsma-Byham, B., and Witter, M. P. (1997). GABAergic presubicular projections to the medial entorhinal cortex of the rat. J. Neurosci. 17, 862-874.

Whittington, M. A., Stanford, I. M., Colling, S. B., Jefferys, J. G., and Traub,
R. D. (1997). Spatiotemporal patterns of gamma frequency oscillations tetanically induced in the rat hippocampal slice. J. Physiol. 502, 591-607.

Whittington, M. A., Traub, R. D., and Jefferys, J. G. (1995). Synchronized oscillations in interneuron networks driven by metabotropic glutamate receptor activation. Nature 373 , 612-615.

Womelsdorf, T., Schoffelen, J. M., Oostenveld, R., Singer, W., Desimone, R., Engel, A. K., and Fries, P. (2007). Modulation of neuronal interactions through neuronal synchronization. Science 316, 1609-1612.

Yan, X. X., and Garey, L. J. (1997). Morphological diversity of nitric oxide synthesising neurons in mammalian cerebral cortex. J. Hirnforsch. 38, 165-172.

Yan, X. X., Jen, L. S., and Garey, L. J. (1996). NADPH-diaphorase-positive neurons in primate cerebral cortex colocalize with GABA and calcium-binding proteins. Cereb. Cortex 6, 524-529.

Conflict of Interest Statement: The authors declare that the research was conducted in the absence of any commercial or financial relationships that could be construed as a potential conflict of interest.

Received: 31 August 2010; accepted: 22 November 2010; published online: 08 December 2010.

Citation: Tamamaki $N$ and Tomioka $R$ (2010) Long-range GABAergic connections distributed throughout the neocortex and their possible function. Front. Neurosci. 4:202. doi: 10.3389/fnins.2010.00202

Copyright (C) 2010 Tamamaki and Tomioka. This is an open-access article subject to an exclusive license agreement between the authors and the Frontiers Research Foundation, which permits unrestricted use, distribution, and reproduction in any medium, provided the original authors and source are credited. 